\title{
Teaching Reform and Practice of Digital Circuit and Logic Design Course Based on Professional Requirements
}

\author{
Heng Wang ${ }^{1, a}$, Quanxin Zheng ${ }^{2}$ \\ ${ }^{1,2}$ School of Electronics and Information Engineering, Jingchu University of Technology, Jingmen \\ 448000, China \\ a wanghengwh@126.com
}

Keywords: Teaching reform, Digital circuit and logic design, Practical teaching

\begin{abstract}
Digital circuit and logic design" is the core of all the professional courses such as the state-level science in electrical engineering, electronic science and technology, information and communication engineering, control science and engineering, computer science and technology and est. Digital circuit and logic design course is very important for a college institute for example, Xian institute's feature is its information science and technology and the function of the course is to make students master the basic analysis method and logical design method of digital circuit. After years of research and exploration, we develop the curriculum concept: combination of theory and practice, reformation of digital technology in the digital circuit and the logic design curriculum[1].
\end{abstract}

\section{The character of digital circuit and logical design}

Digital circuit and logic design is the important professional basic course of electronic and information courses[3]. The main content of digital circuit and logic design course mainly includes the construction of the digital circuit series integrated curriculum system, adjustment the digital circuits and logic design course teaching content, to further streamline introduction of small-scale device and the traditional design method, increase the interpretation of $\mathrm{v}$ HDL language and EDA technology, strengthen the teaching and discussion of modern design methods with the multimedia classroom teaching. The overall goal of the reform is to complete series of digital circuit course system, teaching content and teaching method reform, further improve the teaching level of digital circuit and logic design course through the combination of theory with practice, and to further improve the students' practical ability and innovative spirit. Digital circuit and logic design is computer science and technology in various professional required an important professional foundation course. This course introduces the basic knowledge, basic theory, basic circuit about digital system, also focuses on all kinds of logic circuit in digital system and the basic methods of analysis and design, and the development present situation and the latest technology in this field. The main purpose of setting this course is to make students understand the composition of digital computers and other digital system of various basic logic circuit; be able to skillfully use the relevant knowledge and theory to analyze all kinds of logic circuit; to present all kinds of design requirements for the objective, the integrated use of a variety of methods and techniques to accomplish the design of logic unit and validation. Learning of this course to strengthen students' logical thinking ability, logical, abstract ability, the solution actual problem ability and innovation ability, make the student to grasp the digital hardware system for analysis, design and development of basic skills, lay a solid foundation, wide disciplines for information talent of education high quality.

The purpose of the reform of digital circuit and logic design is to improve students' understanding of computer hardware technology and single-chip microcomputer circuit, and to lay the solid hardware knowledge base for follow-up professional courses. For computer science and technology professional, courses involving computer hardware conclude the circuit analysis, analog electronic technology, digital circuit and logical design, microcomputer principle, composition and interface technology of the computer, for example we can see the following Figure 1 and it can be seen that the digital circuit and logical design plays an essential role in these courses. At the same 
time, the computer hardware technology is the foundation of the computer technology, computer software and application spread from the hardware, therefore, digital circuits and logic design course teaching reform with rich contents and important role.

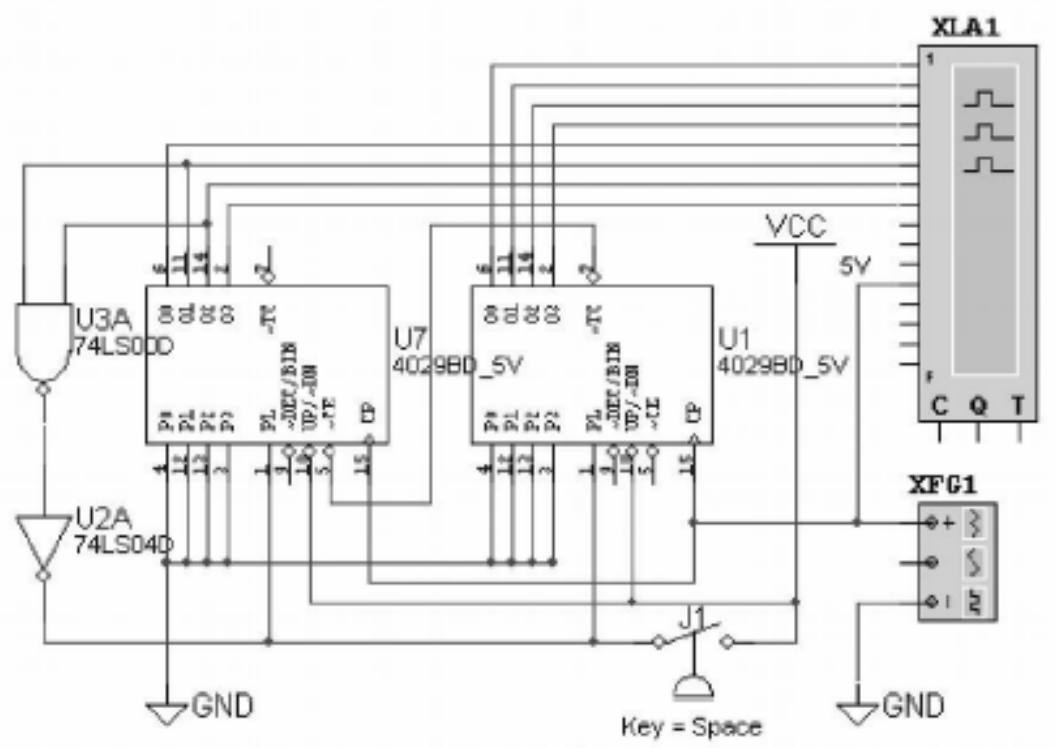

Figure 1: the flow chart of circuit design in sexagesimal calculator

\section{Theory and practice mutually merging with each other}

In terms of teaching content, three-dimensional curriculum system of the digital circuit course with "three modules, three levels" is shown in figure 2[5]. In the teaching practice for many years, to meet the needs of our different professions and pay equal attention to theory and practice of this course, to teach according to their aptitude through in-depth investigation and research of teaching, the course content can be divided in the following 3 modular: first is 64 periods of theory +16 periods of experiment, second the 48 periods of theory +16 periods of experiment, the third is 48 periods of theory +32 periods of experiment. According to the development of electronic technology, update and enrich the teaching contents, the emphasis on the solid foundation at the same time, pay attention to the change of "digital system design" method, especially the establishment of comprehensive and designing experiment teaching content, to make the students learn to use EDA tools to solve the problem of complex digital system design, training students' ability of innovation and engineering practice. Three levels are as follows.

(1) Base layer completes the basic teaching task of digital circuit, the content covers all the teaching section of the digital circuit and the logic design [2-3], and forms a complete set of relevant teaching experiment and comprehensive digital circuit course design. The teaching goal of digital circuit base layer is to cultivate students to form a solid theoretical foundation, analysis, practice ability to deal with problems to lay a solid foundation for subsequent courses.

(2) Composite layer is based on the complement of basic teaching contents in the complete digital circuit to form comprehensive training of students. Mainly need to complete the programmable device and electronic design automation tools of teaching tasks, giving priority to with scale integrated circuit introduced based on the technology of electronic design automation (EDA) hardware description language (VHDL) and the use of development tools QUARTUS II, focuses on the application of complex programmable logic device (CPLD). With comprehensive teaching activities, students can understand the latest large-scale integrated device, grasp the new technology of electronic design automation, understand the VHDL, mass, and the application of large scale logic devices. 


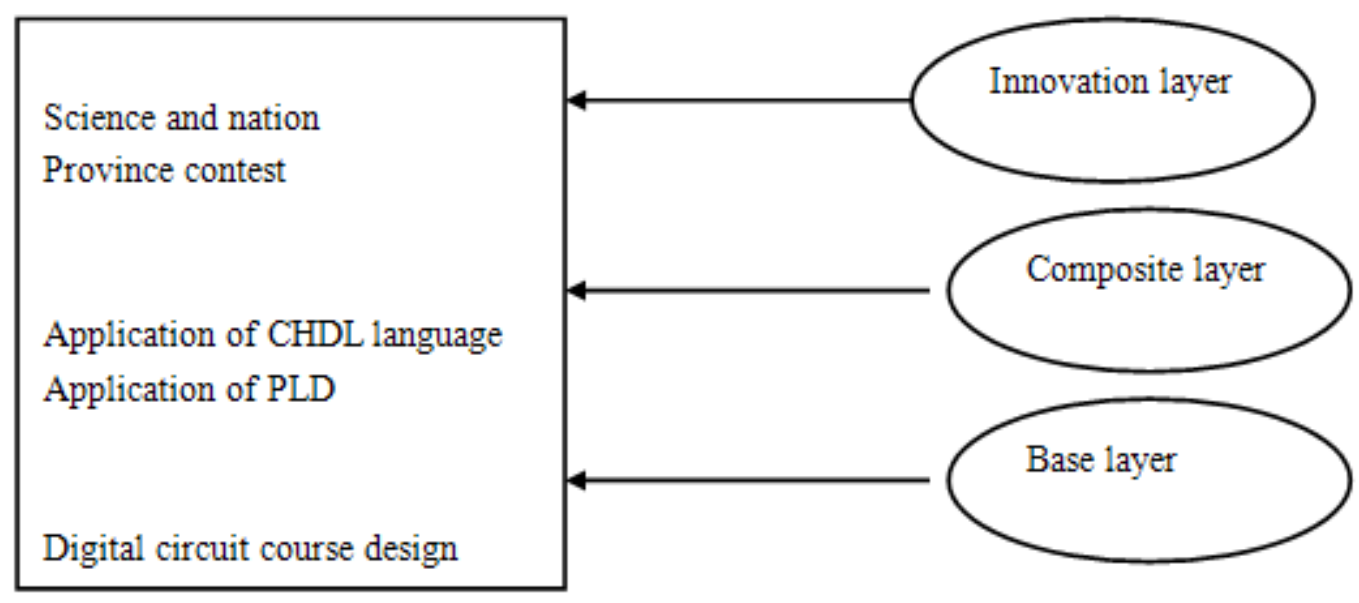

Figure 2 the construction chart of digital circuit and logical design

Innovation layer focuses on the cultivation of innovative talents, is improve content of the course system, and is mainly used to develop the students' ability of engineering practice. To guide students with innovative thinking to participate in all kinds of competitions, widely participate in the national undergraduate electronic design competition, the national college students' smart car competition, the national college students science and technology competition “challenge cup”, the national undergraduate robot competition, the campus student extracurricular scientific research project, teachers' scientific research projects and other kinds of extracurricular activities of science and technology. Teaching goal of innovation layer is to enhance students' engineering design and integrated application of quality, cultivate students' innovation spirit and innovation ability[4]. In the aspect of practice teaching, set to create multi-gradient, muti-platform to develop the students' ability of practice and innovation as the goal, as the mean of updating, integrating and optimizing the practice teaching content of digital circuit, and deal with the relationship between basic and advanced, and then form the "digital circuit experiment" and "digital circuit course design", "EDA technology experiment" and "experimental" programmable logic devices, such as "open experiment" to join each other three experiment module, flexible configuration of experimental teaching system. Some experiments have independent syllabus, independent classes, the independent evaluation, independent calculation for credit, which not only ensures the independence and integrity of each experiment the teaching module, but also ensure the continuity between the experiment modules and progressive. In experiment contents on the attention and theory closely linked, in the experimental method on the relationship between the pay attention to technical and comprehensive and exploratory.

\section{Reform exploration and practice of the course teaching}

3.1Reform of the teaching content. In order to adapt to the development of electronic technology and the application of logic circuit technology, we must reform the digital circuit and logic design course teaching content, further streamline small-scale devices and the content of the traditional design method, strengthen the teaching of modern design methods. For the charpter of "integration logic gates", on the basic understanding of T TL, students are also demanded to master characteristics of T TL. On the arrangement of "combinational logic circuit" section, we should highlight analysis and design of common MSI devices, especially the full adder, decoder and data selector, including the expansion of the scale integrated device and dimension reduction rule is the focus of teaching. For integrated trigger, students need to focus on analysis and interpretation of the basic flip flop, clock control trigger, and the characteristic of the edge trigger master-slave flip-flop. In chapter "temporal logic circuit", Introducing part analyzes the analysis and design of the small-scale integrated device, and focuses on analysis and design method of medium scale logic devices, especially the analysis and design method of synchronous counter. For the semiconductor 
memory, mainly introduces extension method of semiconductor memory and using a ROM to realize combined logic function. Teachers pay attention to invert the scientific research work in scientific research into the teaching content, on the one hand, they reflect in the writing teaching material; on the other hand, they combine their scientific research and engineering design methods and experiences with the classroom teaching, such as the characteristics of various integrated circuits, selection method, and the correct use of methods, such as how to integrated circuit load capacity under the condition of meet the application requirements, the right choice to pull current load or irrigation current load, and take the necessary drive mode. This kind of teaching keeps theory combined with the actual content, fully mobilizes students' learning interest and enthusiasm, cultivates the students' ability of solving practical problems, and has obtained the very good effect.

3.2 Reform of teaching methods. On the teaching methods, to change the traditional teaching model of "cramming education", carry out research study. In order to make the students to learn and understand the basic knowledge of the device and method of use, we let the students to choose their device in market by themselves according to the design requirements in order to make students know the price of the device in the practical work, master methods and matters needed attention during device chosen and buying to make a solid groundwork for the future. Paying attention to the classroom teaching to the extra-curricular activities is also very important. We rely on comprehensive university cultural advantage, extend classroom education on college students' science and technology activities, and actively carry out college students' science and technology innovation activities. Students learn to master knowledge of digital circuit design theory through classroom, design small cars in innovation lab that can identify obstacles which has achieved good results in the undergraduate electronic design contest. Students improve their practice ability and innovation through the combination of theory with practice. Communication engineering professional say in an interview for graduate students: during the study of the "digital circuit and logic design" course, we master the basic theories, basic knowledge and methods of the digital circuit through the teacher's teaching and a variety of ways of learning and achieved success in the postgraduate entrance exam, the digital circuit and the logic design course. One student in communication engineering obtaining very high scores in undergraduate electronic design contest said that she mastered the basic method and thought of the digital circuit design based on the study of "digital circuit and logic design" course which made a guarantee for the subsequent innovation design.

3.3 Reform of teaching means. With the development of science and technology, new teaching means must be reflected in the whole course of teaching. The character of the course "digital circuits and logic design" is rich in content, more charts. The traditional teaching classroom has the certain difficulty in using multimedia technology to make complex graphics intuitive and image easy seen and understood, which is not only convenient for the explanations of the teachers and students' learning, but also will greatly increase the classroom information, solve the problem of less class hour, more content. But classroom teaching can't depend entirely on the multimedia courseware, teachers need to push students thinking, strengthen the interaction between teachers and students, and students from gradual explained so that students understand easily. For example, the "digital circuit and logic design" course mainly adopts the PowerPoint courseware and blackboard writing, the method can mutual complement each other, the effect is better. Set up the "digital circuit and logic design" course website, web site with the teaching of the course, teaching content, characteristics, and provide related information such as the teaching outline, teaching plan, references, and teacher's query. At the same time, we can also establish the online discussions with teachers, online answering questions, online video teaching. Web course can not only meet the needs of the students' self-study, and to provide a reference for the teachers' classroom teaching, provide convenience to the teachers and students of online learning, answering questions and discussing the interactive environment; provide convenience for the teachers and students of data query and retrieval functions.

3.4 The construction of practice platform. All scientific research laboratory of the college are open to undergraduate "all-day long", students can work in the laboratory to come into contact with 
the latest technology, to strengthen the practice teaching effect. College will work with a foreign company in the United States to build a bright guide joint laboratory which is open to students, so that the students can use the advanced circuit design software in the international first-class laboratory. Electronic information system and automatic innovation laboratory provides students with the independent innovation of learning platform, achieves the double function of project research and taking part in all kinds of science and technology competitions, effectively makes up for the class teaching to cultivate students' practical ability and creative thinking.

\section{Summary}

"Digital circuit and logic design" is a course with strong basic and application. Sticking to the old unchanged way of teaching is not applicable, also the excessive emphasis on the reform, to reform for reform is not desirable. Since the important role of Digital circuit and logic design in communication engineering discipline makes its educational reform work more careful and cautious. In the teaching, we should accumulate more thinking and more observation, follow the principle of "teaching effect for the first point" to improve the students' interest in learning, provide a basis for the future professional course, to adapt to the change of new technology and new products. In short, teaching is an art, and the teaching process is a complicated system project. To build a more complete and reasonable "digital circuit and logic design" teaching system also needs to constantly explore and practice.

\section{Acknowledgements}

Research on Provincial Teaching Reform in Hubei Province in 2016.

"Study on the school enterprise docking and integration of Electrical Engineering Specialty in local colleges and universities”, Project number:2016423.

\section{References}

[1] B.S. Zhao. Practice and exploration of digital circuit experiment teaching reform[J]. Journal of education in Heilongjiang province, 2005, 01(10):27-30.

[2] L.P. Wang. Multi-dimensional interaction analysis of digital circuit classroom teaching[J]. Journal of Tonghua normal university, 2006, 27 (6):121-122.

[3] J.M. Cui. EDA simulation technology of electrical and electronic [M]. Beijing: higher education press, 2004.

[4] Q. Zhou, Y.N. Xu. Practice and design of basic analysis of circuit teaching innovation [J]. Journal of Guilin institute of electronics industry, 2004, 4(1):115-116.

[5] Y. Wang. Design and development of digital logic circuit experiment system [J]. Journal of laboratory research and exploration, 2008 (12):12-14. 